\title{
Commercial Artificial Sweeteners Might Affect Pregnant and Nursing Mice Mammary Gland. A Histological Study
}

\author{
Manar M. Al-Hasan, Fatma Al-Qudsi \\ Biology Department, King AbdulAziz University, Jeddah, KSA \\ Email: falqudsi@kau.edu.sa
}

How to cite this paper: Al-Hasan, M.M. and Al-Qudsi, F. (2020) Commercial Artificial Sweeteners Might Affect Pregnant and Nursing Mice Mammary Gland. A Histological Study. Journal of Biosciences and Medicines, 8, 95-108. https://doi.org/10.4236/jbm.2020.812010

Received: November 8, 2020

Accepted: December 14, 2020

Published: December 17, 2020

Copyright $\odot 2020$ by author(s) and Scientific Research Publishing Inc. This work is licensed under the Creative Commons Attribution International License (CC BY 4.0).

http://creativecommons.org/licenses/by/4.0/

\section{(c) (i) Open Access}

\begin{abstract}
The use of artificial sweeteners as non-nutritive food additive is becoming very common nowadays. The aim of this research was to study the effect of commercial artificial sweeteners consumption on the adult mouse mammary gland in pregnancy (18-day pregnancy) and 3 weeks nursing. A commercial artificial sweetener solution was given to pregnant mice of treated groups 50 $\mathrm{mg} / \mathrm{kg}$ body weight, from day one of pregnancy till the end of 3 weeks nursing. Controls were given distilled water. The histological studies of the mammary gland of treated animals showed some changes. In treated 18-day pregnant mothers; the amount of adipose cells seemed to increase and the amount of lipid droplets within the alveoli seemed to increase compared to the controls. Also alveoli in the treated mammary gland sections appeared to be larger and less in number compared to the controls. In 3 weeks treated nursing mothers the amount of milk and lipid droplets in the alveoli decreased compared to the controls. The mammary gland circumference of treated 18-day pregnant mothers was significantly smaller compared to the controls, while it was significantly larger in 3 weeks treated nursing mothers compared to the controls. These results show that artificial sweeteners disturbed the arrangement of the histological structure in the mammary gland of pregnant and nursing mice. Awareness should be raised to restrict the use of artificial sweeteners to people with diabetes or who are in medical need.
\end{abstract}

\section{Keywords}

Mammary Gland, Artificial Sweeteners, Pregnant Mice. Adipose Tissue, Sorbitol, Aspartame, Nursing

\section{Introduction}

Artificial sweeteners (A.S.) are being added by individuals to hot brewages such 
as coffee or tea. Also (A.S.) are being added to a wide range of manufactured food products such as most sugar-free sweets and chewing gum, many baked products, toothpaste and some medicines [1] [2] [3] [4] [5]. The commercial artificial sweeteners present in the markets, consist of a combination of several artificial sweeteners and some other substances; this can be seen clearly from the ingredient labels of the different brands of artificial sweeteners.

The use of (A.S.) helped lots of people with diabetes to cope with their disease, and also it helped obese persons to stick to diets in order to lose weight. Also (A.S.) present in medicines helped with better acceptance of several medicines by patients. While the presence of artificial sweeteners in toothpaste and sugar free chewing gum helped reduce tooth decay. On the other hand, much recent research showed that specific types of A.S. might have potential toxicity [6]. Chronic exposure was done on Wistar strain albino rats. Aspartame $(75 \mathrm{mg} / \mathrm{kg})$ was given for 90 days orally. This led to detectable methanol circulation in the blood. It is known that methanol metabolites may cause oxidative stress in brain regions [7]. When $(40 \mathrm{mg} / \mathrm{kg})$ aspartame dissolved in distilled water was given for 2, 4 and 6 weeks by gastric tube to adult Wistar strain albino rats, it was observed that aspartame ingestion on the long-term caused oxidative stress induction in rat cerebral cortex [2]. When normal albino rats were given (10-mg sor$\mathrm{bitol} / \mathrm{kg}$-body weight/day), for 24 weeks, sorbitol toxicity was seen on the retinas of these normal albino rats where it affected retinal micro vessels, pigment epithelium, neural retina and glial cells. It was concluded that sorbitol may play a role in the setup of diabetic retinopathy [8]. Sorbitol ingestion on the long-term caused cataract and neuropathy in diabetic Sprague-Dawley rats, when given (100 mg/kg) sorbitol for 40 weeks [9].

Mice are a very good mammalian model to use in research, as it is easy to handle and manipulate [10].

All female mammals have important organs responsible for milk production to nourish newborns; these organs are the mammary glands [11] [12] [13] [14]. The mouse has five pairs of mammary glands [15]. The mammary gland consists of a connective tissue, or stroma also called the mammary fat pad [16]. The stroma consists of cellular and noncellular components such as collagen and elastin [17] [18]. It includes primarily fibroblasts, adipocytes, immune cells, blood vessels, nerves, smooth muscle fibers and lymph nodes [19] [20]. The stroma or fat pad supports the growth of epithelial tissue that forms several structures such as ducts, ductules, terminal end buds, and alveoli [15]. Ducts merge in one primary collecting duct, which opens to the body surface by the nipple.

There are two cell types of mammary epithelium: basal and luminal cells. The basal epithelium consists of myoepithelial cells which surround the luminal epithelium. These cells are responsible for the movement of milk during lactation, and the secretion of basement membrane components during all developmental stages. The myoepithelial cells are characterized by their thickness, and continuity during development, but during pregnancy and lactation they become discontinuous and form stellate-shaped cells [15] [19]. The luminal cells are cu- 
boidal or columnar cells [16] [18] [19]. Their apical surface contacts the lumen of ducts, ductules, and alveoli. These cells have no direct contact with the basement membrane [19]. The luminal epithelium becomes functionally differentiated during lactation, where it becomes responsible for milk synthesis and secretion [18] [19]. Breast cancer arises in the luminal epithelial cells [21].

In mice and rats, the peak of mammary gland differentiation occurs in pregnant females during the 19 - 21 days of pregnancy. Where, rapid and continuous increase in the mammary gland epithelium leads to the formation of alveolar buds, which gives rise to alveolar lobules. The alveolar lobules increase in size and number, while the stroma thins. This occurs in response to hormones (estrogen, progesterone and prolactin). By day 19 of pregnancy, the alveoli fill the fat pad and the mammary gland is capable of milk production [15] [19].

Involution is the process by which the mammary gland returns to its non-lactating state [15] [22]. It occurs due to several factors, including decreased levels of prolactin, due to milk accumulation and compression of the vasculature, factors in milk that promote apoptosis of the luminal epithelium, and increased activity of basement membrane-degrading enzymes [19]. During involution alveoli begins to collapse and extra cellular matrix breakdown [14] [15] [23]. Then alveolar epithelial cells start to undergo apoptosis, myoepithelium becomes thick, and luminal epithelium degrading becomes clear. Followed by an increase in adipocytes, and a decrease in the size of the alveolar lobules, also the epithelium appears disorganized and dense stroma appears around the ducts. Near the end of involution stage, all of the alveoli appear collapsed and disorganized, and the amount of stroma surrounding alveoli increases [15] [19].

Malignant breast cancer is the ninth leading death cause in Saudi women [24] [25] [26] [27] [28], and the second in the United States of America [29]. Some studies predict an increase of breast cancer cases in Saudi Arabia in the coming few decades [26] [30].

The debate on whether A.S. has a potential role in causing cancer is been going on for some time in the scientific research, where some studies relate the dosage of some A.S. to the induction of the formation of malignant tumors [31] [32] [33] [34]. While other studies found no relation between A.S. consumption and the incidence of malignant tumor formation [35].

Regarding the intense research done on causes of breast cancer, and the research done on A.S. toxicity, it seemed interesting to test the effects of commercial artificial sweeteners on adult mammary gland during pregnancy and end of lactation period to detect the changes in its histological structure.

The uniqueness of this research lies in the use of normal doses of commercial artificial sweeteners present in the market, mimicking the human use of these sweeteners, therefore, replicating the actual scenario that takes place in everyday life.

\section{Methodology}

All experimental procedure was approved by the Biology department at King 
Abdulaziz University. Experiments were done at King Fahd Medical Research Center.

The animals were purchased from the Animal House Unit at King Fahd Medical Research Center at King Abdul Aziz University. Swiss, white, roadless adult mice (60 females and 30 males) were used, with body weight between 30 to 35 grams. Throughout the experiment, they were fed corn cob pellets with a water bottle at 12:12 hour light: dark and temperature at $22^{\circ} \mathrm{C} \pm 2{ }^{\circ} \mathrm{C}$.

A commercial artificial sweetener available in the market was purchased from local supermarket and used for the experiment. It contained $98.4 \%$ sorbitol and $1.6 \%$ aspartame.

Mating:

The estrus stage was determined by the method of [36]. Both male and female (in estrus stage) were placed for 24 hours in one cage for mating. After 24 hours, females were separated from males. Then the female vagina was examined for the presence of a vaginal plug as a sign of fertilization. Day one was considered the day of the presence of the vaginal plug.

Dose estimation and Administration:

According to the study of Al-Qudsi and Al-Hasan (2019), the dose used in this research was $50 \mathrm{mg} / \mathrm{kg}$ body weight (as it was the most commonly used dose). The preparation and administration of the dose was also done according to the same study.

Study Design:

Pregnant mice were divided into two groups: Control group (C) and Treated group $(\mathrm{T})$ each of the control and treated groups were divided into two subgroups ( $\mathrm{C} 1$ and $\mathrm{T} 1$ ) were sacrificed on day 18 of pregnancy to examine the effect of A.S. on the mammary gland in late pregnancy, and subgroups (C2 and T2) were sacrificed by the end of the third week of nursing to examine the effect of A.S. on the mammary gland in the end of nursing period. Each subgroup was composed of 5 mice. In the control group, pregnant mice were orally dosed by gavage needle given $1 \mathrm{ml}$ of distilled water until the end of nursing stage, while in the treated group, pregnant mice were given $(1 \mathrm{ml}$ of the experimental solution) at a temperature of $40^{\circ} \mathrm{C}$ until the end of the nursing stage.

\section{Sample Collection:}

All mothers were monitored daily for activity and behavior. All experimental mothers were weighed at the beginning of the experiment and before dissection, then anesthetized and dissected. Mammary gland was taken from the mothers according to the method of [37]. Mammary glands number (4) were taken for whole mounting. Right mammary gland number 2, 3 were taken for histology. See Figure 1.

Whole mount preparation:

Mammary gland whole mount was prepared according to the method of [37].

Histological techniques:

The Mammary gland was fixed in formalin solution $10 \%$. Then, dehydrated, and embedded in hard paraffin wax at a temperature of $58^{\circ} \mathrm{C}$. Wax blocks were 


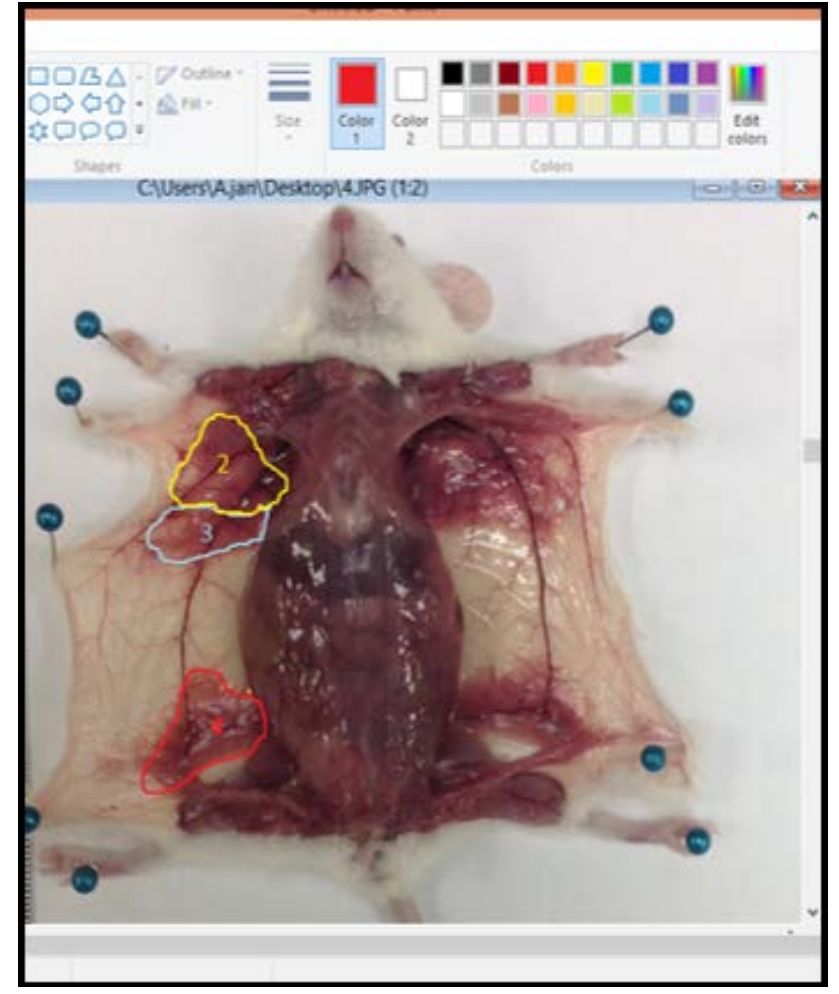

Figure 1. Method of measuring the circumference of mammary gland number 2,3 and 4 .

cut to vertical sectioning of 4 micron thick. Sections were stained by Ehrlich's hematoxylin and eosin [38].

Photography:

All dissected mothers were photographed by an Ipad 4 for morphometry and general anatomy. A ruler was put near the samples during photo taking as a scale.

Slide photographing:

Stained sections were examined and photographed using a compound microscope (Olympus BX51) connected to a camera model number (Olympus DP72) while stained whole mounts were examined and photographed using a dissecting microscope (Olympus SZX16) connected to a camera model number (Olympus DP25) at King Fahd Center for Medical Research.

Morphometric studies:

Morphometric studies were performed on 18-day pregnant mothers, and 3 weeks nursing mothers. The circumference of mammary glands number 2, 3 and 4 was taken (see Figure 1). The measurements were taken from the photos taken during dissection. Image tool program was downloaded free from (http://cme.msu.edu/cmeias/), and was used to conduct morphological measurements.

Statistical analysis:

Data was collected into excel, then transferred to (SPSS 22). The test used with normal distribution was Anova, Student-Neuman Keul test. In case of abnormal 
distribution Man-Whitney U test was used from the non-parametric test. Significance was at $\mathrm{p}<0.05$.

\section{Results}

Effect of artificial sweetener on mother's weight:

A non-significant decrease in the weight of treated 18 day pregnant mothers and 3 weeks nursing mothers was seen compared to the controls.

Effect of artificial sweetener on mother's mammary gland circumference:

The circumference of mammary glands No 2, 3 and 4 in 18 day pregnant treated mothers was less compared to the control. The decrease was very significant in mammary gland $2 \mathrm{p}<0.001$. While in 3 weeks treated nursing mothers the circumference of mammary glands No 2, 3 increased. It was significantly increased in mammary gland No $4 \mathrm{p}=0.028$ compared to the controls (see Figure 2).

Effect of artificial sweetener on the histological structure of mice mammary gland:

An examination of the cross section of control mammary gland from 18-day pregnant mother showed that the mammary gland consisted of lobules separated by loose inter-lobular connective tissue). Alveoli had one layer of cuboidal or columnar luminal epithelium cells and myoepithelial cells based on the basal lamina. A loose intra-lobular connective tissue surrounded the alveoli. Alveoli contained residual milk. Lipid droplets within apical parts of cells in the lumen. It also contained blood vessels and adipose cells. See Figure 3(A) for low magnification and Figure 4(A) for high magnification.

An examination of the cross section of mammary gland from treated 18-day pregnant mothers showed that it was similar to the control. However, the adipose cells seemed to be more than the control. Also lipid droplets within the alveoli seemed to be less than of the control. Alveoli in the treated sections

\section{Effect of artificial sweeteners on mammary gland circumference}

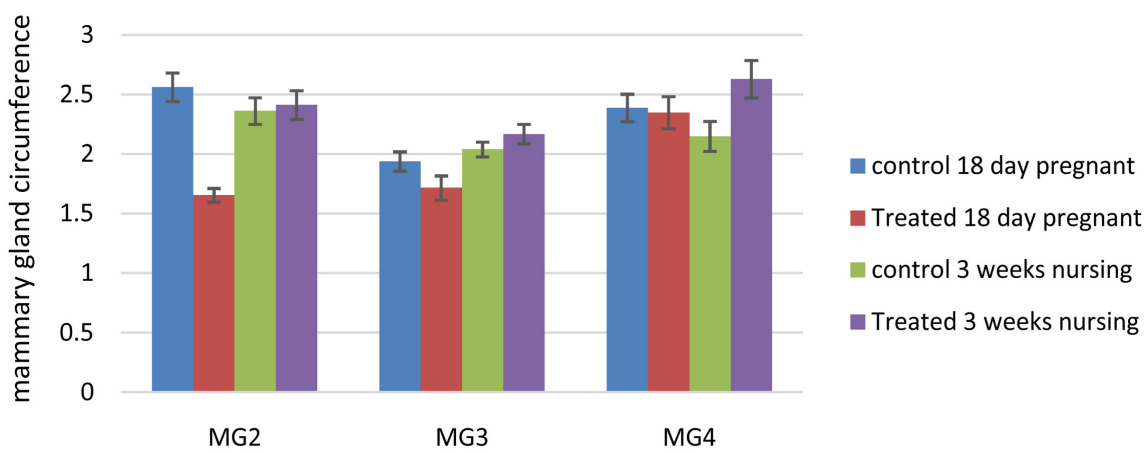

Figure 2. Graph showing the effect of artificial sweetener on the circumference of mammary gland number 2, 3 and 4 of 18 days pregnant and 3 weeks nursing mothers in control and treated groups. (MG) mammary gland Values are mean \pm standard error $(\mathrm{M} \pm$ SE) taken from (5) samples for each group. $\left(^{\star}\right) \mathrm{P}<0.05$. 

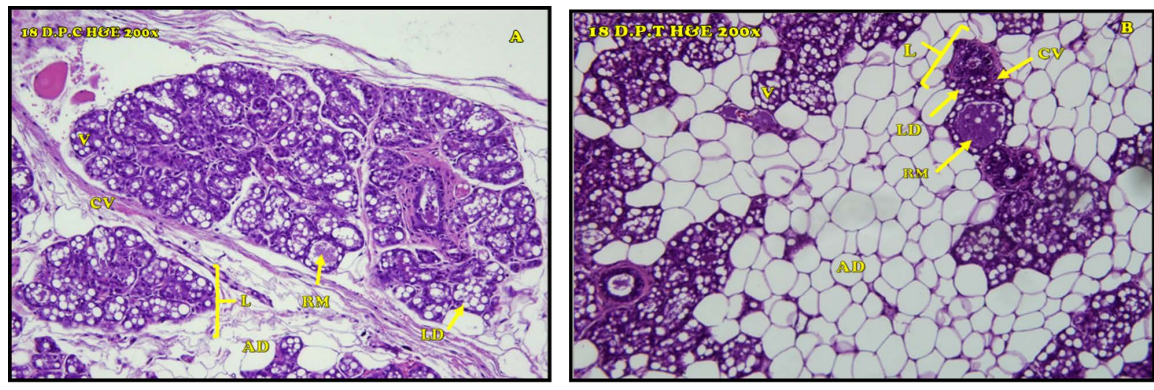

Figure 3. Photomicrograph of cross section of mammary gland from 18 days pregnant mother mice. Magnification 200× (H\&E). (A) Control. (B) Treated. Adipose cells (AD), Lobule (L), Alveoli (V), Connective tissue (CV), Residual milk (RM), Lipid droplets (LD). Note the adipose cells in the treated pregnant mice seem to be more than the control. Also lipid droplets within the alveoli seemed to be more abundant than of the control. Alveoli in the treated appear to be larger and less in number compared to the control.
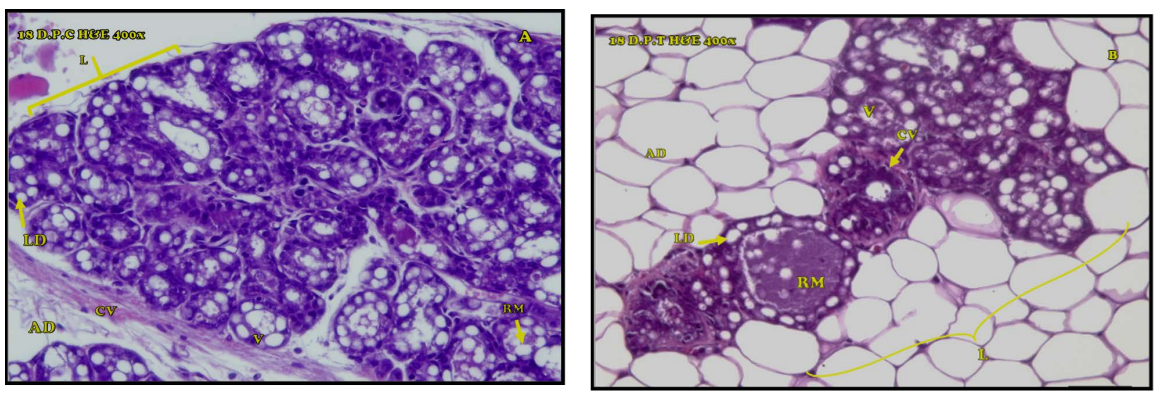

Figure 4. Enlargement of the photomicrograph of cross section of mammary gland from 18 days pregnant mother mice in Figure 3. Magnification $400 \times(\mathrm{H} \& \mathrm{E})$. (A) Control. (B) Treated.

appeared to be larger and less in number compared to the control. See Figure 3(B) for low magnification and Figure 4(B) for high magnification).

An examination of the cross section of control mammary gland from 3 weeks nursing mother showed that the mammary gland consisted of lobules separated by loose inter-lobular connective tissue. The alveoli filled the fat pad. Alveoli had one layer of cuboidal or columnar luminal epithelium cells and myoepithelial cells based on the basal lamina. A loose intra-lobular connective tissue surrounded the alveoli. Alveoli contained residual milk. Lipid droplets within apical parts of cells and in the lumen. It also contained blood vessels and adipose cells. Myoepithelial cells formed a discontinuous layer around the alveoli. See Figure 5(A) for low magnification and Figure 6(A) for high magnification.

An examination of the cross section of the treated mammary gland from 3 weeks nursing mother showed that it was similar to the control. However, the adipose cells in the treated mice seemed to be less compared to the control. Also the amount of milk in the alveoli of treated groups seemed to be less than the control group. And the lipid droplets seemed to be less than the control. Also the fusion of several alveoli was seen. Also the alveoli in the treated section appeared to be much bigger than the control. See Figure 5(B) for low magnification and Figure 6(B) for high magnification. No difference was seen in the whole mount 


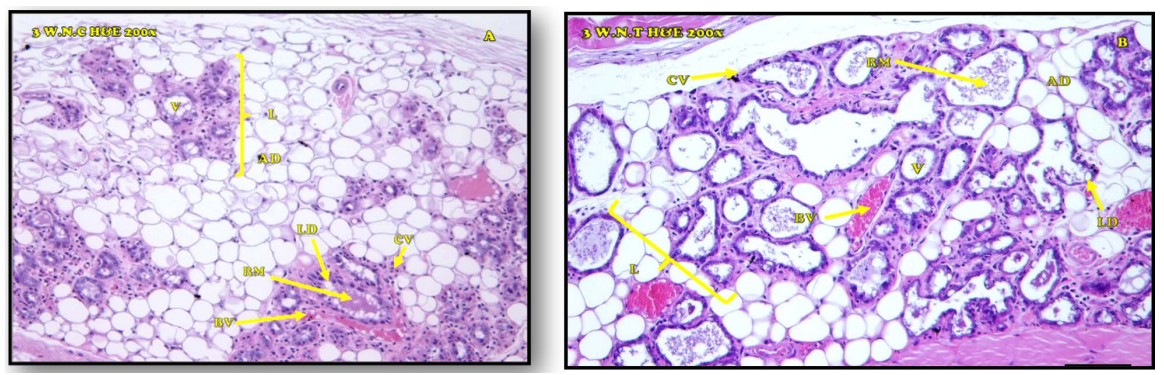

Figure 5. Photomicrograph of cross section of mammary gland from 3 weeks nursing mother mice. Magnification 200× (H\&E). (A) Control. (B) Treated. Adipose cells (AD), Lobule (L), Alveoli (V), Connective tissue (CV), Residual milk (RM), Lipid droplets (LD), Blood vessel (BV). Note the adipose cells in the treated mice seemed to be less compared to the control. Also the amount of milk in the alveoli of the treated group seemed to be less than the control group. The lipid droplets seem to be less than the control. Also the fusion of several alveoli is seen $\left(^{*}\right)$. The alveoli in the treated section seen to be much bigger than the control.
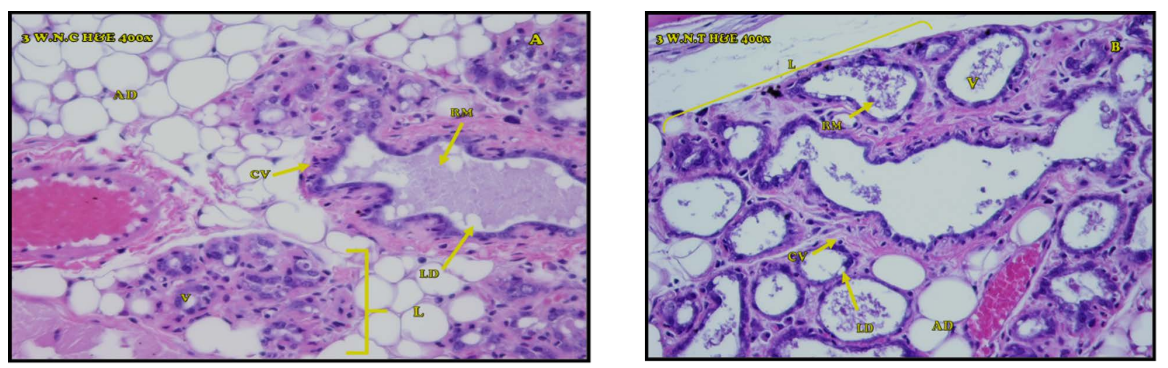

Figure 6. Enlargement of the photomicrograph of cross section of mammary gland from 3 weeks nursing mother mice seen in Figure 5.

of the mammary gland number 4 of 18 days treated pregnant females compared to the controls. However the mammary gland number 4 of the 3 weeks nursing treated mothers appeared to have reduced amount of milk compared to the controls, see Figure 7.

\section{Discussion}

In recent years, artificial sweeteners or sugar substitutes became more popular and are used in most foods and beverages in today's market. Women are using artificial sweetener as means to help prevent weight gain or diabetes [2] [39].

In this study no significant decrease in weight of treated pregnant mothers of 18 days or 3 weeks nursing mothers was seen. This was mentioned in previous studies when using maternal dosages of 500, 1000, 2000 and $4000 \mathrm{mg} / \mathrm{kg}$ body weight aspartame on 15 - 18 days of pregnancy [40].

In this study the histological sections of the mammary gland of the control group in 18 days pregnant and 3 weeks nursing mothers mice were typical to other studies [15] [19] [41].

This study results have shown that the adipose cells in the treated 18 days pregnant mice mammary gland sections seemed to be more than those seen in the control sections. During this stage the mammary gland is preparing for lactation 

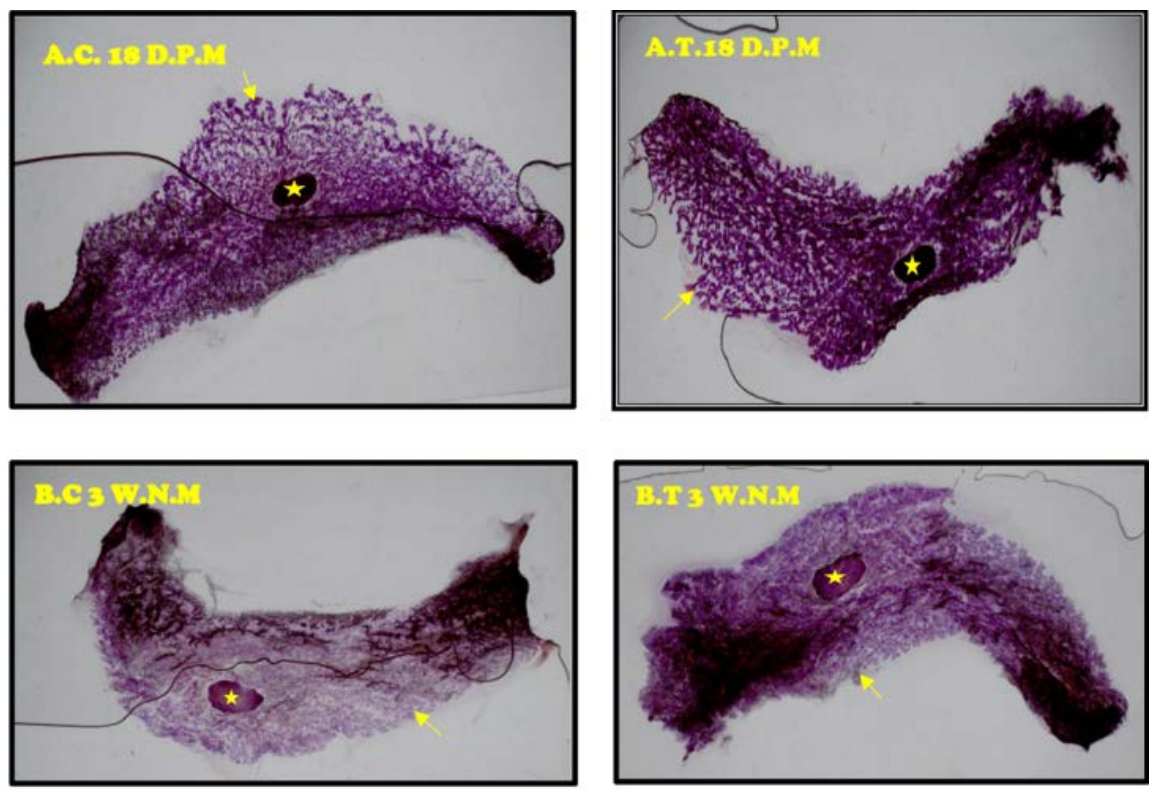

Figure 7. Whole mount of mammary glands number 4. (A) 18 days pregnant mother. (B) 3 weeks nursing mother. (Star) Lymph node. (Arrow) TEB. (C) Control. (T) Treated (all same magnification see bar). Note the abundance of white parts (milk) of mammary gland in control 3 weeks nursing mothers (BC3) on the left compared with the treated one (CT3) on the right.

as offspring delivery in mice is on day 19 - 20. Usually in this phase the lobules that contain the alveoli take a large part of the mammary gland while the adipose tissue area is reduced. Mammary gland adipose tissue plays a vital role in the formation of the ducts and alveoli during the nursing phase [42].

Scientists explained that estrogen is responsible for the organization of adipose tissue, where the accumulation of alcohol urges to raise the levels of the hormone estrogen and thus increase adipose cells during pregnancy [43] [44] [45]. It seems that the branching of ducts and formation of alveoli was slower in the treated mothers mammary glands compared to the controls; taking a longer time to fill the fat pad. This is contradictory to what was seen with 4 weeks mouse neonates from artificial sweetener fed mothers, where terminal end buds were seen growing quickly and retracting as they reached the end of the fat pad [46]. It seems that the effect of artificial sweeteners differs with age and hormone balance.

In this study the mammary glands of treated 3 weeks nursing mothers showed that the milk was removed quickly from the ducts during lactation as ducts seemed to be empty, it might be also that the milk production was less than that of the controls. This might indicate that artificial sweeteners altered phase change timing in the mammary gland; such as duct and alveoli formation and milk production in pregnant and nursing mouse mammary gland, and beginning of involution process later on. [47] explained that alcohol affects the secretion and function of numerous hormones especially the prolactin hormone reducing milk secretion. Also studies suggested that the mammary gland adipose 
tissue played a vital role in duct and alveoli formation for lactation, then their regression after lactation [42].

In this study, it seems that the artificial sweeteners had an effect on the mammary gland adipose tissue which affected the epithelial tissue formation of ducts and alveoli.

The histological changes taking place in the involution period or end of lactation period seem to be very interesting as they represent a complete reorder of the dominant tissue in the mammary gland. The resistance of some cells or types of tissue to go with the flow at this stage might result in uncontrolled niches that might be the nucleus of tumors later on.

Breast cancer cases have increased dramatically in the last ten years and are expected to be more in the coming years [24] [26] [29]. Studies have shown that mammary gland adipose tissue plays a vital role in Breast cancer [48].

Regarding the histological and morphometric results of mammary gland in this study, it could be concluded that, it seems that the factor giving the mammary gland its dimension here is the area and number of the alveoli. As the ducts seemed to be very small and few in the 18 days pregnant and more and much larger in the 3 weeks nursing treated mothers compared to the controls. Unfortunately we were not able to study milk quantity and composition of the nursing mothers consuming artificial sweeteners, as its result might have shed the light on its possible effects on offspring. More studies should be conducted in this domain using the artificial sweetener present in the market with the dose used by normal individuals.

It should be noted that the results of this study showed that commercial artificial sweeteners altered the histological structure and phase timing although the study has just used commercial artificial sweeteners present in the market and used the normal dose consumed by normal individuals. Regarding the amount of dose taken on daily basis in real life by individuals it seems that In addition of intaking some amounts of artificial sweeteners through medications and toothpaste, many pregnant and nursing females use these nonnutritive sweeteners to avoid gaining excess weight during pregnancy and nursing which might increase the dose taken daily to more than the permitted amount. Therefore more studies should be done to understand the mechanism of the effect of the artificial sweeteners commercial combinations and raise the awareness of the prospective role of these nonnutritive sweeteners in different illnesses.

\section{Conclusion and Recommendation}

This study has shown the effect of daily consumption of commercial artificial sweetener solution ( $50 \mathrm{mg} / \mathrm{kg}$ body weight) on mammary gland in pregnant and nursing mice. It caused an increase in adipose cells, lipid droplets and larger alveoli in 18-day pregnant mice compared to the control, while decreasing adipose cells, milk and lipid droplets in 3 weeks nursing mice. The dose used in this study is the one used by many females in the cities of Makkah and Jeddah in 
Saudi Arabia. Moreover regarding the effects it had on the mother's mammary gland, therefore it is advisory to eliminate the use of artificial sweeteners in normal diets and restrict it to patients who really need it.

\section{Acknowledgements}

We would like to thank King AbdulAziz University and King Fahad Medical research center for providing support to do this research.

\section{Conflicts of Interest}

None.

\section{Financial Support}

This research was supported by King Abdul-Aziz city for science and technology (Grant No. 336 - . أط- (35).

\section{References}

[1] Islam, M.S. and Sakaguchi, E. (2006) Sorbitol-Based Osmotic Diarrhea: Possible Causes and Mechanism of Prevention Investigated in Rats. World Journal of Gastroenterology: WJG, 12, 7635. https://doi.org/10.3748/wjg.v12.i47.7635

[2] Mourad, I.M. and Noor, N.A. (2011) Aspartame (A Widely Used Artificial Sweetener) and Oxidative Stress in the Rat Cerebral Cortex. Journal of Pharmaceutical and Biomedical Sciences, 2, 4-10.

[3] Ozen, I.T., Karav, S. and Eksi, A. (2014) Variability of Sorbitol/Xylitol Content in Pomegranate (Punica granatum) Juice as Affected by Processing Conditions. International Journal of Food and Nutrition Science, 3, 4-7.

[4] Siripurkpong, P., et al. (2014) Sorbitol Has No Significant Effects on 3T3-L1-Adipogenesis and Adiponectin Synthesis and Secretion. Science \& Technology Asia, 19, 64-73.

[5] Washburn, C. and Christensen, N. (2012) Sugar Substitutes: Artificial Sweeteners and Sugar Alcohols.

[6] Whitehouse, C.R., Boullata, J. and McCauley, L.A. (2008) The Potential Toxicity of Artificial Sweeteners. AAOHN Journal, 56, 251-261.

https://doi.org/10.1177/216507990805600604

[7] Iyyaswamy, A. and Rathinasamy, S. (2012) Effect of Chronic Exposure to Aspartame on Oxidative Stress in Brain Discrete Regions of Albino Rats. Journal of Biosciences, 37, 679-688. https://doi.org/10.1007/s12038-012-9236-0

[8] Ramadan, G.A. (2007) Sorbitol-Induced Diabetic-Like Retinal Lesions in Rats: Microscopic Study. American Journal of Pharmacology and Toxicology, 2, 89-97. https://doi.org/10.3844/ajptsp.2007.89.97

[9] Ota, A., et al. (2013) Effects of Long-Term Treatment with Ranirestat, a Potent Aldose Reductase Inhibitor, on Diabetic Cataract and Neuropathy in Spontaneously Diabetic Torii Rats. Journal of Diabetes Research, 2013, Article ID: 175901. https://doi.org/10.1155/2013/175901

[10] Hedrich, H. (2004) The Laboratory Mouse. Academic Press, Cambridge.

[11] Hassiotou, F. and Geddes, D. (2013) Anatomy of the Human Mammary Gland: Current Status of Knowledge. Clinical Anatomy, 26, 29-48. 
https://doi.org/10.1002/ca.22165

[12] Sordillo, L., Shafer-Weaver, K. and DeRosa, D. (1997) Immunobiology of the Mammary Gland. Journal of Dairy Science, 80, 1851-1865. https://doi.org/10.3168/jds.S0022-0302(97)76121-6

[13] Vorbach, C., Capecchi, M.R. and Penninger, J.M. (2006) Evolution of the Mammary Gland from the Innate Immune System? Bioessays, 28, 606-616. https://doi.org/10.1002/bies.20423

[14] Watson, C.J. (2006) Key Stages in Mammary Gland Development-Involution: Apoptosis and Tissue Remodelling That Convert the Mammary Gland from Milk Factory to a Quiescent Organ. Breast Cancer Research, 8, 203. https://doi.org/10.1186/bcr1401

[15] Richert, M.M., et al. (2000) An Atlas of Mouse Mammary Gland Development. Journal of Mammary Gland Biology and Neoplasia, 5, 227-241. https://doi.org/10.1023/A:1026499523505

[16] Hennighausen, L. and Robinson, G.W. (2005) Information Networks in the Mammary Gland. Nature Reviews Molecular Cell Biology, 6, 715-725.

https://doi.org/10.1038/nrm1714

[17] Capuco, A.V. and Akers, R.M. (2009) Management and Environmental Influences on Mammary Gland Development and Milk Production. In: Managing the Prenatal Environment to Enhance Livestock Productivity, Springer, Berlin, 259-292. https://doi.org/10.1007/978-90-481-3135-8_9

[18] Krause, S. (2008) Stromal-Epithelial Interactions in the Mammary Gland: Development of a Tissue Morphogenesis Model. Sackler School of Graduate Biomedical Sciences (Tufts University), Medford.

[19] Masso-Welch, P.A., et al. (2000) A Developmental Atlas of Rat Mammary Gland Histology. Journal of Mammary Gland Biology and Neoplasia, 5, 165-185. https://doi.org/10.1023/A:1026491221687

[20] Van Keymeulen, A., et al. (2011) Distinct Stem Cells Contribute to Mammary Gland Development and Maintenance. Nature, 479, 189-193. https://doi.org/10.1038/nature10573

[21] Gudjonsson, T., et al. (2002) Normal and Tumor-Derived Myoepithelial Cells Differ in Their Ability to Interact with Luminal Breast Epithelial Cells for Polarity and Basement Membrane Deposition. Journal of Cell Science, 115, 39-50.

[22] Monks, J., et al. (2002) Do Inflammatory Cells Participate in Mammary Gland Involution? Journal of Mammary Gland Biology and Neoplasia, 7, 163-176. https://doi.org/10.1023/A:1020351919634

[23] Macias, H. and Hinck, L. (2012) Mammary Gland Development. Wiley Interdisciplinary Reviews. Developmental Biology, 1, 533-557. https://doi.org/10.1002/wdev.35

[24] Al-Eid, H. and Arteh, S. (2005) Cancer Incidence Report Saudi Arabia. Kingdom of Saudi Arabia: Ministry of Health, Saudi Cancer Registry, Riyadh, 1-99.

[25] Al-Eid, H.S. and Arteh, S. (2003) Cancer Incidence Report Saudi Arabia 2003. Kingdom of Saudi Arabia Ministry of Health National Cancer Registry, Riyadh.

[26] Alotaibi, R.M., et al. (2018) Breast Cancer Mortality in Saudi Arabia: Modelling Observed and Unobserved Factors. PLOS ONE, 13, e0206148. https://doi.org/10.1371/journal.pone.0206148

[27] Lozano, R., et al. (2012) Global and Regional Mortality from 235 Causes of Death for 20 Age Groups in 1990 and 2010: A Systematic Analysis for the Global Burden of Disease Study 2010. The Lancet, 380, 2095-2128. 
https://doi.org/10.1016/S0140-6736(12)61728-0

[28] Mokdad, A.H., et al. (2014) The State of Health in the Arab World, 1990-2010: An Analysis of the Burden of Diseases, Injuries, and Risk Factors. The Lancet, 383, 309-320. https://doi.org/10.1016/S0140-6736(13)62189-3

[29] Siegel, R.L., Miller, K.D. and Jemal, A. (2020) Cancer Statistics, 2020. CA: A Cancer Journal for Clinicians, 70, 7-30. https://doi.org/10.3322/caac.21590

[30] Ibrahim, E.M., et al. (2008) The Present and the Future of Breast Cancer Burden in the Kingdom of Saudi Arabia. Medical Oncology, 25, 387-393.

https://doi.org/10.1007/s12032-008-9051-5

[31] Soffritti, M., et al. (2005) Aspartame Induces Lymphomas and Leukaemias in Rats a L'aspartame Induce Linfomi e Leucemie Nei Ratti. European Journal of Cancer, 10, 107-116.

[32] Soffritti, M., et al. (2006) First Experimental Demonstration of the Multipotential Carcinogenic Effects of Aspartame Administered in the Feed to Sprague-Dawley Rats. Environmental Health Perspectives, 114, 379-385.

https://doi.org/10.1289/ehp.8711

[33] Soffritti, M., et al. (2010) Aspartame Administered in Feed, Beginning Prenatally through Life Span, Induces Cancers of the Liver and Lung in Male Swiss Mice. American Journal of Industrial Medicine, 53, 1197-1206. https://doi.org/10.1002/ajim.20896

[34] Soffritti, M., et al. (2007) Life-Span Exposure to Low Doses of Aspartame Beginning during Prenatal Life Increases Cancer Effects in Rats. Environmental Health Perspectives, 115, 1293-1297. https://doi.org/10.1289/ehp.10271

[35] Gallus, S., et al. (2007) Artificial Sweeteners and Cancer Risk in a Network of Case-Control Studies. Annals of Oncology, 18, 40-44.

https://doi.org/10.1093/annonc/mdl346

[36] Byers, S.L., et al. (2012) Mouse Estrous Cycle Identification Tool and Images. PLoS ONE, 7, e35538. https://doi.org/10.1371/journal.pone.0035538

[37] Plante, I., Stewart, M.K. and Laird, D.W. (2011) Evaluation of Mammary Gland Development and Function in Mouse Models. JoVE (Journal of Visualized Experiments), 53, e2828. https://doi.org/10.3791/2828

[38] Drury, R. and Wallington, E. (1980) Carelton's Histology Technique. 5th Edition, Oxford University Press, Oxford, New York, Toronto.

[39] Modi, S. and Borges, V. (2005) Artificial Sweeteners: Boon or Bane. International Journal of Diabetes in Developing Countries, 5, 1-6. https://doi.org/10.4103/0973-3930.26753

[40] Butchko, H.H., et al. (2002) Aspartame: Review of Safety. Regulatory Toxicology and Pharmacology, 35, S1-S93.

[41] Morroni, M., et al. (2004) Reversible Transdifferentiation of Secretory Epithelial Cells into Adipocytes in the Mammary Gland. Proceedings of the National Academy of Sciences, 101, 16801-16806. https://doi.org/10.1073/pnas.0407647101

[42] Zwick, R.K., et al. (2018) Adipocyte Hypertrophy and Lipid Dynamics Underlie Mammary Gland Remodeling after Lactation. Nature Communications, 9, Article No. 3592. https://doi.org/10.1038/s41467-018-05911-0

[43] Gill, J. (2000) The Effects of Moderate Alcohol Consumption on Female Hormone Levels and Reproductive Function. Alcohol and Alcoholism, 35, 417-423. https://doi.org/10.1093/alcalc/35.5.417

[44] Heine, P., et al. (2000) Increased Adipose Tissue in Male and Female Estrogen Re- 
ceptor- $\alpha$ Knockout Mice. Proceedings of the National Academy of Sciences, 97, 12729-12734. https://doi.org/10.1073/pnas.97.23.12729

[45] Nagata, C., et al. (2007) Association of Maternal Fat and Alcohol Intake with Maternal and Umbilical Hormone Levels and Birth Weight. Cancer Science, 98, 869-873. https://doi.org/10.1111/j.1349-7006.2007.00464.x

[46] Al-Qudsi, F.M. and Al-Hasan, M.M. (2019) In Utero Exposure to Commercial Artificial Sweeteners Affects Mice Development and Mammary Gland Structure. Environmental Science and Pollution Research, 26, 5054-5064. https://doi.org/10.1007/s11356-018-3935-5

[47] Heil, S.H. and Subramanian, M.G. (1998) Alcohol and the Hormonal Control of Lactation. Alcohol Health and Research World, 22, 178.

[48] Rybinska, I., et al. (2020) Adipocytes in Breast Cancer, the Thick and the Thin. Cells, 9, 560. https://doi.org/10.3390/cells9030560 